\title{
Effect of tailwater depth and model scale on scour at culvert
} outlets

\section{R. A. Day, S. L. Liriano and W. R. White}

\section{K. A. Mazurek and M. R. Ahsan}

The authors have made a very constructive and commendable effort to research the effect of tailwater on the scour mechanism in a non-cohesive bed that is situated downstream of a culvert. As we are currently pursuing research in this area, this particular paper has drawn our attention. We feel obliged to discuss some of the issues presented in this paper.

The authors have discussed findings of their experiments and also have made an effort to review some past experiments conducted by other researchers. In this regard they have presented Table 1, which summarises information on these previous experiments. However, some of the information presented in the table seems to be either erroneous or incomplete. For example, Ali and Neyshaboury ${ }^{7}$ did not vary the tailwater depth, but kept it nearly constant in all of their runs. They conducted their research for variable jet heights. Ali and $\operatorname{Lim}^{14}$ did not limit their study to a submergence ratio $\left(H / d_{0}\right)$ of $0 \cdot 49$. And in the case of the research conducted by Rajaratnam and MacDougall, ${ }^{20}$ the submergence ratio was approximately $1 \cdot 0$.

The study has carried out measurements continuously in dynamic conditions from the initiation of scouring to the equilibrium state. The authors have introduced a definition of the concept of equilibrium state. They consider the state to be in equilibrium when the rate of the scour profile in any hour has been less than the median sediment size. It would have been very useful for the readers to know how long it took to reach the equilibrium state in different series of tests. Also, the authors have referred to scour profile in their definition of equilibrium state. It is not clear whether reference was made to scour depth or scour length in this definition.

The study observed the rather expected relation of scouring depth with the densimetric Froude number, $F_{0}$. While researching the effect of the tailwater on the scour, the authors observed a downward trend of scour depth for higher tailwater depths. This finding might have been more effectively presented by having $d_{\mathrm{sc}} / d_{0}$ as the dependent variable of $H / d_{0}$ for different ranges of $F_{0}$. This approach, which would locate the magnitude of the submergence ratio where the scouring depth would tend to be constant, was used by Ali and $\operatorname{Lim}^{14}$ and was discussed by Johnston and Halliwell. ${ }^{23}$

The reviewers also would like to point out that the reference detail of Rajaratnam and MacDougall ${ }^{20}$ is inaccurate. Apart from some confusion, this paper should be credited for the fact that it made an attempt to define the equilibrium state of the dynamic scour profile.

\section{REFERENCE}

23. Johnston A. J. and Halliwell A. R. Discussion on 'Local scour caused by submerged wall jets'. Proceedings of the Institution of Civil Engineers, 1987, 83, Pt 2, 875-886. 